\title{
EBSD Analysis of the Primary Austenite Grains in Lamellar Graphite Cast Iron
}

\author{
Marcos G. López ${ }^{1}$ (1) $\cdot$ Luke N. Brewer $^{2} \cdot$ Juan M. Massone ${ }^{1} \cdot$ Roberto E. Boeri $^{1}$
}

Received: 4 September 2018 / Revised: 5 February 2019 / Accepted: 26 April 2019 / Published online: 9 May 2019

(c) ASM International 2019

\begin{abstract}
This work investigates the size and morphology of the primary austenite grains present in lamellar graphite cast iron. Samples of lamellar graphite iron were cast and austempered during the post-solidification cooling stage in order to preserve part of the original austenite at room temperature. Electron backscatter diffraction technique was applied to reveal the regions of different crystalline orientation of the austenite. The eutectic colonies and the last-to-freeze areas were also examined by color etching of the same regions previously analyzed by electron backscatter diffraction. The results reveal that the solidification units of lamellar graphite iron are formed by austenite grains that include several eutectic colonies inside, all of which have the same crystalline orientation as the primary austenite grain. For all the samples studied, it can be confirmed that there are no eutectic colonies with a different crystalline orientation than that of the primary austenite dendrites.
\end{abstract}

Keywords Lamellar graphite iron $\cdot$ Austenite grains $\cdot$ Eutectic colonies $\cdot$ EBSD $\cdot$ Color etching

\section{Introduction}

The solidification of gray cast irons has always been a particularly complex research subject since conventional metallographic techniques were not capable of revealing the interaction between the primary austenite and the graphite during solidification. The as-cast microstructure of gray cast irons is conformed by a matrix composed of ferrite and/or pearlite, which is the result of the solid-state transformation of the primary austenite below the eutectoid temperature. This transformation absolutely masks the primary austenitic structure. For this reason, special procedures must be applied if the morphology and size of the primary austenite grains in cast irons are to be studied. Most of these procedures involve techniques such as interrupted solidification by quenching experiments $[1,2]$ or direct austempering after solidification (DAAS) [3, 4]. A comparison between these two techniques shows that DAAS has the advantage of preserving a great part of the original austenite at room temperature, making

Marcos G. López

marcosl@fi.mdp.edu.ar

1 INTEMA, UNMdP - CONICET, Mar del Plata, Argentina

2 Metallurgical and Materials Engineering Department, The University of Alabama, Tuscaloosa, AL, USA it possible to analyze the original microstructure by electron backscattering diffraction (EBSD). DAAS allowed, for the first time, the characterization of the ingot macrostructure of normally solidified gray cast iron samples, showing the presence of grains of different size [5, 6]. A DAAS-treated sample of gray cast iron is presented in Fig. 1.

Additionally, the microstructure of cast iron samples can be examined after the application of specific color etching techniques, such as the Motz reagent [7]. Motz reagent is sensitive to Si segregation, and it reveals the location of the last-to-freeze volumes (LTF) and primary dendrites in gray cast irons [8]. The application of the Motz reagent on lamellar graphite iron (LGI) has allowed characterizing the interaction between the austenite and the graphite during the growth of the eutectic colonies of this material [9-12].

The results obtained both by DAAS and color etching gave experimental support to a new explanation of the solidification of gray cast irons $[3,4,9,12]$. This proposal states that for gray cast irons the eutectic solidification starts with the independent nucleation and growth of austenite dendrites and graphite from the melt. As dendrites grow, they interact with graphite particles, conforming solidification units that can be described as grains of austenite with a dendritic substructure that contain a very large number of graphite particles inside. This mechanism has also been proposed to be valid for hypo and hypereutectic gray irons $[6,13]$. 
Nevertheless, there are still some significant controversies involving the solidification mechanism of these alloys, as some of the literature work states that the austenite growth will be affected by the carbon content of the cast iron [14, 15]. The solidification of eutectic and hypereutectic LGI is often described as dominated by the presence of eutectic colonies or cells, consisting of nearly spherical arrays of austenite and graphite, as shown schematically in Fig. 2 [16]. Some of these studies make no reference to the presence and influence of austenite dendrites at all, assuming that from each austenite nucleus a single eutectic cell is formed [17].

Recently, Stefanescu et al. [18] proposed a more advanced explanation of the eutectic LGI solidification in a work that

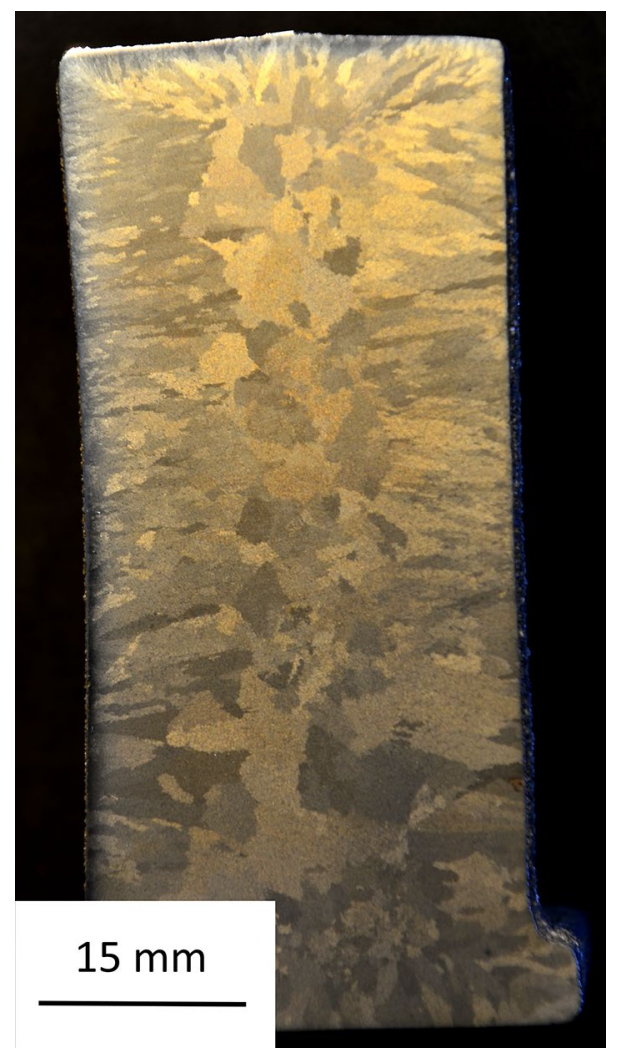

Fig. 1 DAAS-treated sample showing the presence of austenite grains of different size

Fig. 2 Frequent representation of the solidification of eutectic and hypereutectic LGI [16] considers both the experimental evidence of the DAAS treatment and the representation of the solidification presented in Fig. 2. This theory states that the eutectic cells can nucleate and grow as independent units mostly in the liquid, but it also proposes the formation of a limited amount of primary austenite in eutectic LGI that may solidify independently from the eutectic cells, depending on the cooling rate. They name the eutectic cells or colonies as "eutectic grains" claiming that, especially for the case of eutectic and hypereutectic LGI, these eutectic units could conform independent grains with a different crystallographic orientation than the primary austenite grain. According to their explanation, these eutectic grains should be found at the low cooling rate regions present in the central equiaxed zones of cast samples.

The explanation proposed by Stefanescu et al. leads to the conclusion that it should be possible to find small regions of different crystallographic orientation, coincident with the eutectic colonies or grains from Fig. 2, located inside the larger primary austenite grains observed by the naked eye in Fig. 1. In order to verify this proposal, it becomes necessary to investigate in detail the structure of the grains revealed by DAAS using EBSD. The method of EBSD has proved to be an excellent tool for the determination of the crystallographic orientation of austenite grains in cast irons [19,20], and the careful application of this technique should clearly identify any volume of different crystallographic orientation inside the larger grain.

The main goal of the present research is to examine the solidification structure of lamellar cast irons using EBSD, applying the knowledge gained to clarify the solidification mechanisms of this material.

\section{Methodology}

Two melts (A and B) were produced at the melting laboratory of INTEMA using a medium frequency $50 \mathrm{~kg}$ capacity induction furnace. Regular melting and metal treatment procedures were used. Both melts were inoculated with $0.1 \mathrm{wt}$ \% FeSi75 and were used to produce $60-\mathrm{mm}$ diameter
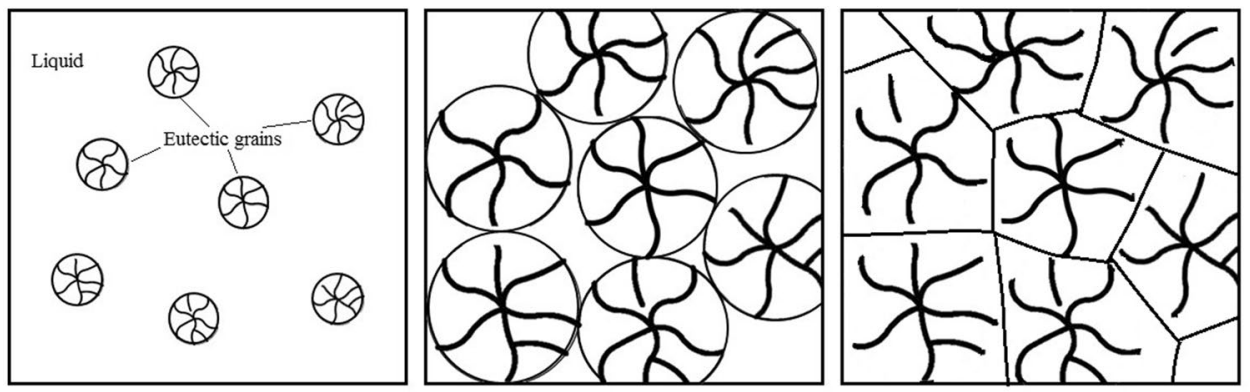
lamellar graphite iron spheres cast in resin bonded sand molds.

Table 1 lists the chemical composition of the melts. Small amounts of alloying elements were used. These are necessary to provide sufficient hardenability to carry out the DAAS procedure [4].

Once all the samples were cast, the DAAS technique was applied to retain the solidification austenite at room temperature. The DAAS-treated samples were then sectioned along their cross section, ground and polished. The stage of final polishing was carried out in a vibratory polisher using colloidal silica of $0.02 \mu \mathrm{m}$ particle size for two hours.

EBSD was then used to map the crystallographic orientation of the austenite grains in the samples that were previously subjected to DAAS. The EBSD tests were performed at the Central Analytical Facility of The University of Alabama employing a Tescan Lyra FESEM equipped with an EDAX EBSD detector. Each scan covered an area of 0.75 by $1 \mathrm{~mm}$ at steps of $2 \mu \mathrm{m}$. The analysis was focused at the equiaxed grains located at the central zone of the samples. The indexed phases for the analysis were austenite and ferrite, leaving the graphite as non-indexed points. For the sake of the clarity, in the post-processing, only the austenite phase was plotted in the inverse pole figure (orientation) maps and no data cleaning routines were employed. High-angle grains boundaries were identified by misorientations of $\geq 10^{\circ}$ between adjacent, indexed austenite points. Additionally, in order to analyze a whole austenite grain (of several square millimeters size), several contiguous scans were stitched together into one orientation map.

Finally, the microstructure of the samples was revealed by etching with the Motz reagent. The examination was performed in the same regions previously analyzed by EBSD.
In order to be able to locate the same regions for both analysis, several microhardness indentations were made on the DAAS-treated samples near some of the grain boundaries observed by the naked eye.

\section{Results and Discussion}

The graphite morphology obtained for each melt is shown in Fig. 3. Both Melt A and Melt B present type A flake graphite, with a noticeable amount of proeutectic kish graphite for the case of hypereutectic Melt B.

The solidification macrostructures of the melts, obtained after the application of the DAAS treatment, are shown in Fig. 4 . The areas analyzed belong to the cross section of the samples and include both the central equiaxed zone and the columnar zone. The size of the austenite grains in Fig. 4 makes it possible to observe them by the naked eye after a regular etching, just as it was formerly reported [9, 19]. At this length scale, there are no signs of the existence of smaller grains inside of the larger austenite grains. However, no conclusions can be made from the visual inspection alone; a more detailed analysis will be achieved after the application of the EBSD technique.

The EBSD maps for samples of both melts are presented in Figs. 5 and 6. The crystallographic orientation of the austenite is shown as an inverse pole figure map with respect to the $\mathrm{X}$ direction in the surface of the sample. Both maps show the graphite (not indexed points) in white and the ferrite in black. The white diamond-shaped marks are Vickers indentations used to match the orientation maps with the optical images in Figs. 7 and 8.
Table 1 Chemical composition of the two melts produced

Fig. 3 Graphite morphologies observed for Melts A and B

\begin{tabular}{lllllllll}
\hline Melt & \multicolumn{2}{l}{ Content, wt.\% } & \multicolumn{1}{l}{} \\
\cline { 2 - 8 } & $\mathrm{C}$ & $\mathrm{Si}$ & $\mathrm{Mg}$ & $\mathrm{Mn}$ & $\mathrm{Cu}$ & $\mathrm{Ni}$ & $\mathrm{S}$ & $\mathrm{P}$ \\
\hline $\mathrm{A}$ & 3.25 & 2.96 & 0.006 & 0.48 & 0.67 & 0.48 & 0.020 & 0.054 \\
$\mathrm{~B}$ & 3.75 & 2.75 & 0.005 & 0.45 & 0.65 & 0.79 & 0.014 & 0.035 \\
\hline
\end{tabular}
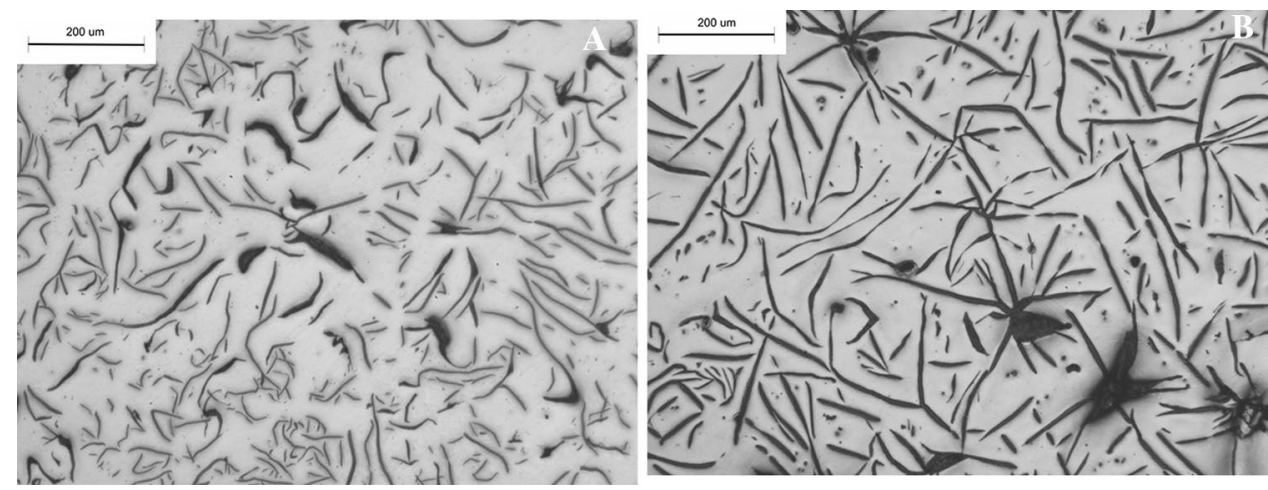
Fig. 4 Solidification macrostructures obtained for Melts A and $\mathrm{B}$
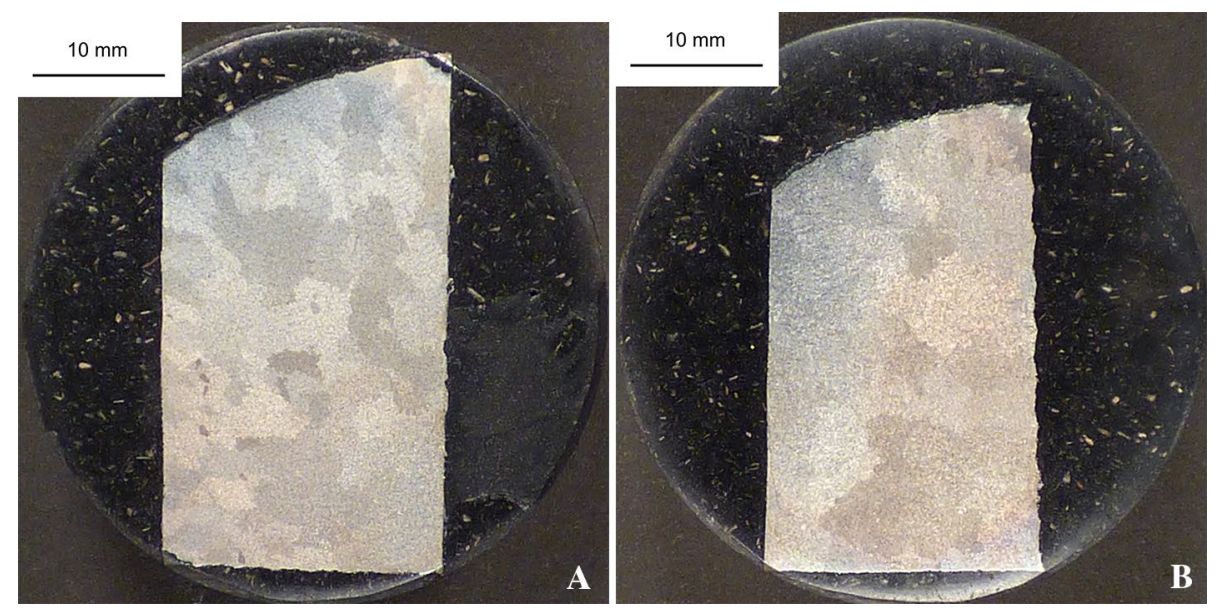

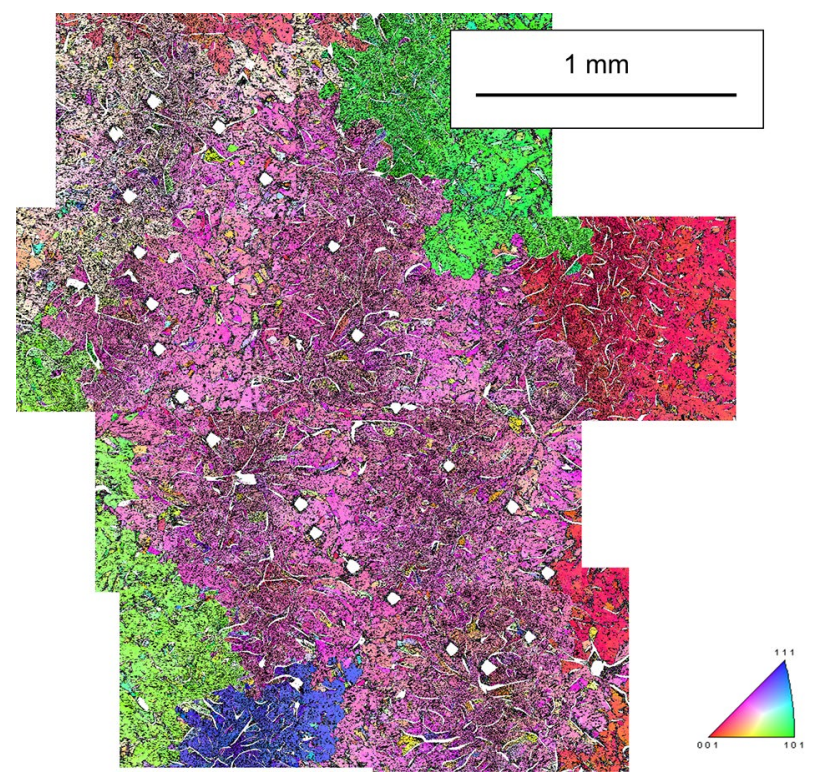

Fig. 5 EBSD map of a whole austenite grain from an LGI sample of Melt A

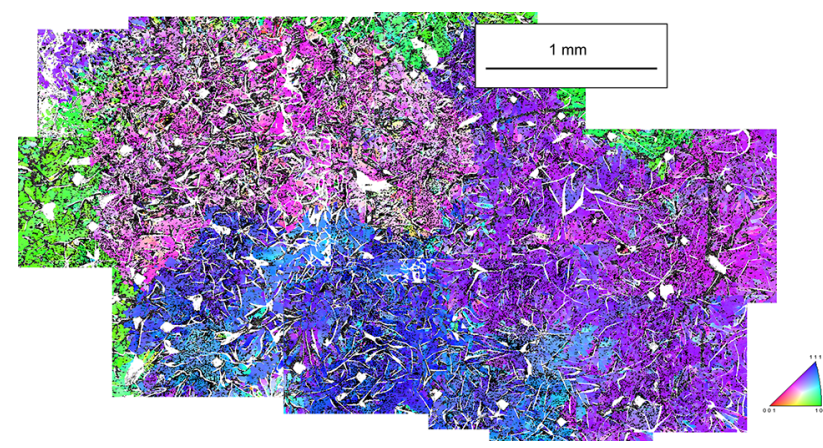

Fig. 6 EBSD map of a whole austenite grain from an LGI sample of Melt B
The EBSD maps presented in Figs. 5 and 6 cover an entire austenite grain of the central equiaxed zone of each sample shown in Fig. 4. The same grains visible in optical microscopy are revealed by EBSD as having a uniform crystalline orientation of austenite. The borders between neighboring grains are clearly identified. These observations confirm the results obtained by DAAS; the austenite dendrites grow at relatively large extent into the samples of LGI, and each grain formed contains many flake graphite units inside.

Additional information regarding the eutectic cells or colonies can be obtained after the application of the Motz reagent. Figure 7 a shows the color etched microstructure for Melt A on the same region previously analyzed by EBSD. The LTF regions are shown in orange in this figure, contouring the eutectic colonies that appear in green. The same microstructure is shown in Fig. 7b, adding white lines to mark the position of the grain boundaries determined by EBSD. Besides, in a similar manner to what was done by Ruxanda et al. [21], the microsegregation pattern was highlighted by blue lines. This allows revealing the approximate shape and size of the eutectic colonies. The same procedure was followed for Melt B, obtaining the result shown in Fig. 8. In both cases, several eutectic colonies are found inside each region identified as an austenite grain by the EBSD mappings of Figs. 5 and 6.

When comparing the same regions analyzed first by EBSD (Figs. 5 and 6) and later by color etching (Figs. 7 and 8), it is noteworthy that the eutectic colonies revealed by color etching have the same crystalline orientation as the parent austenite grain revealed by EBSD. This means that the eutectic colonies are not independent grains, even for the case of the low cooling rate areas found at the center of the $60-\mathrm{mm}$ diameter spheres studied. For this reason, it can be confirmed that the eutectic colonies or cells originate from the interaction of growing austenite dendrite arms and graphite. Consequently, eutectic colonies are not units that 
Fig. 7 (a) Microstructure of the same area analyzed by EBSD for the sample of Melt A (color etched). (b) Same image with the LTF regions marked in blue and the EBSD-determined grain boundaries marked in white
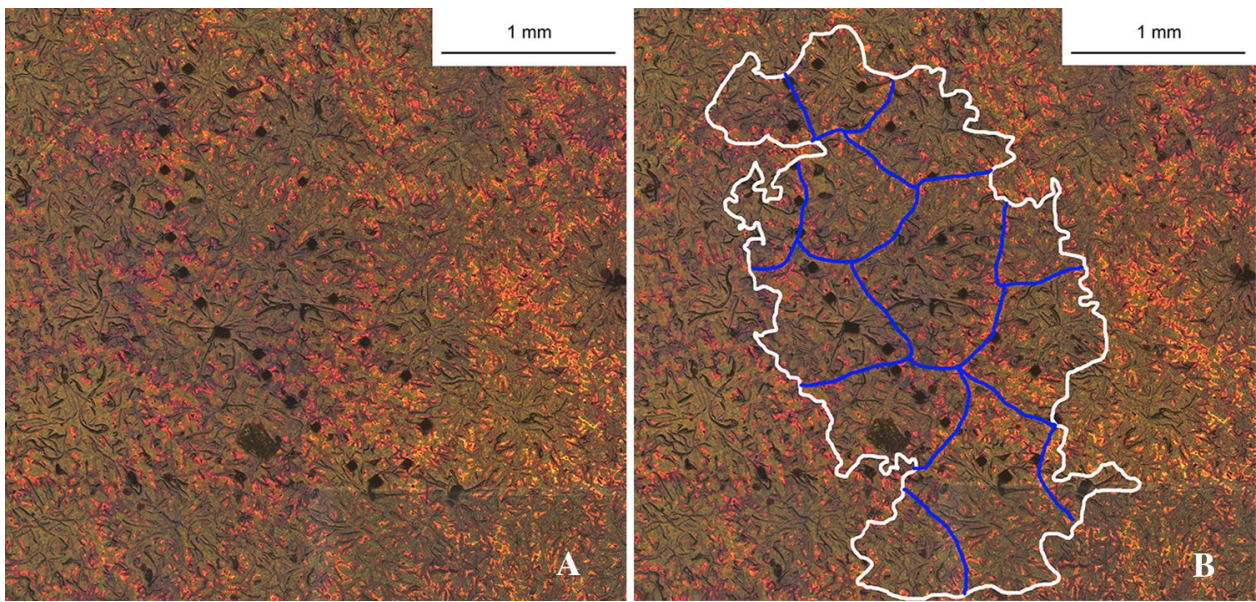

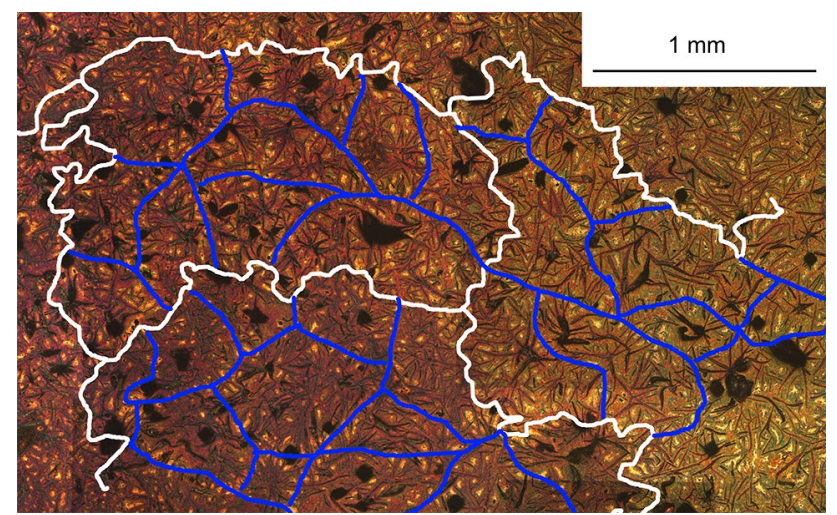

Fig. 8 Microstructure of the same area analyzed by EBSD for the sample of Melt B (color etched)

nucleate and grow independently from the primary austenite, as proposed by the schematics of Fig. 2. This finding contradicts the explanation proposed by Stefanescu et al. and refutes the existence of a so-called eutectic grain for eutectic and hypereutectic compositions of LGI.

Some other key features arise from a further analysis of Figs. 7 and 8, the first of them being discussed next. It can be observed both from Figs. 7 and 8 that grain boundaries are mostly coincident with some of the microsegregation patterns, meaning that, in those cases, the grain boundaries are also LTF regions. However, there are exceptions to this rule, as there are a few eutectic colonies, such as that shown in Fig. 9, that share the crystallographic orientation of two different grains. In these cases, the grain boundaries do not match with any LTF region, as can be confirmed from Fig. 10 which shows a magnification of an area of Fig. 7. This suggests that, for these cases, the flake graphite "rosettes" that conform the eutectic colonies started growing in contact with the liquid and, during the eutectic growth, they got in contact with two dendrites of austenite at relatively the same time. According to Fig. 10, a cooperative

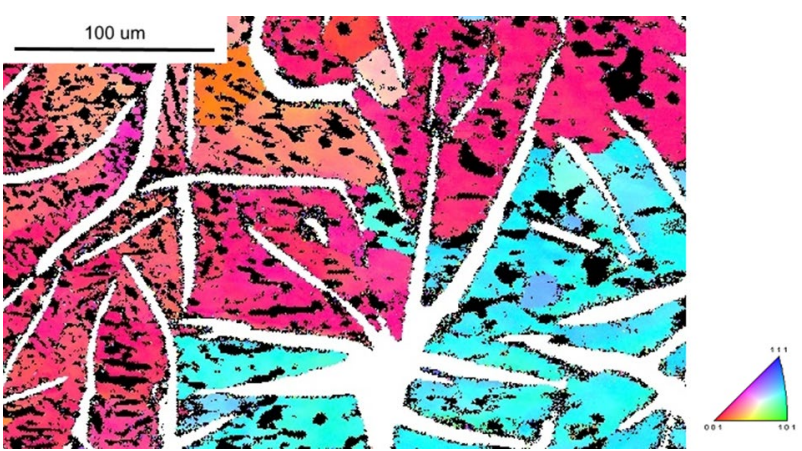

Fig. 9 EBSD map from the sample of Melt B showing a flake graphite unit in contact with two different grains

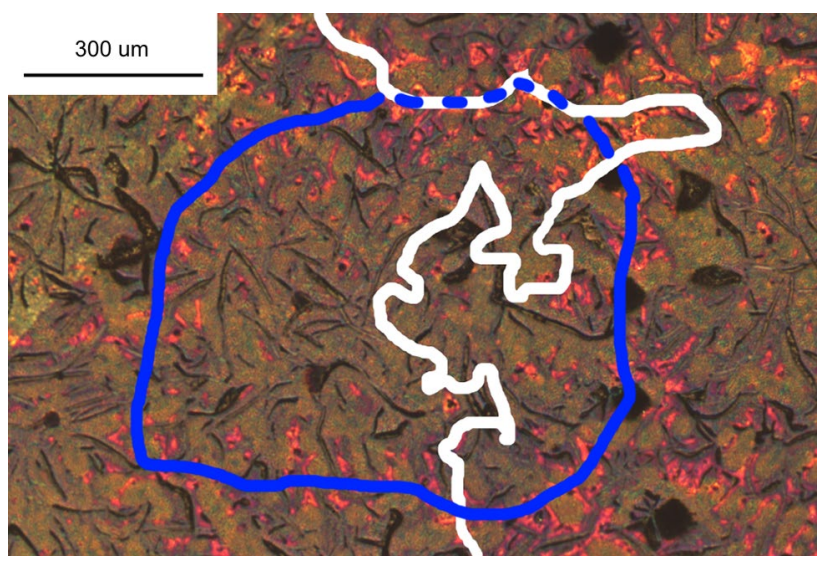

Fig. 10 Zoom of Fig. 7 showing the LTF regions of a eutectic colony (blue) located at a grain boundary (white)

growth between the graphite and both dendrites was established for this case.

The other key feature to be discussed can be observed when the EBSD maps for samples of Melts A and B are shown at higher magnification, as shown in Fig. 11. 
Fig. 11 Higher magnification EBSD maps for samples of Melts A and B. Red arrow points to a single $\sim 50$ microns crystallite of differing orientation from the rest of the colony
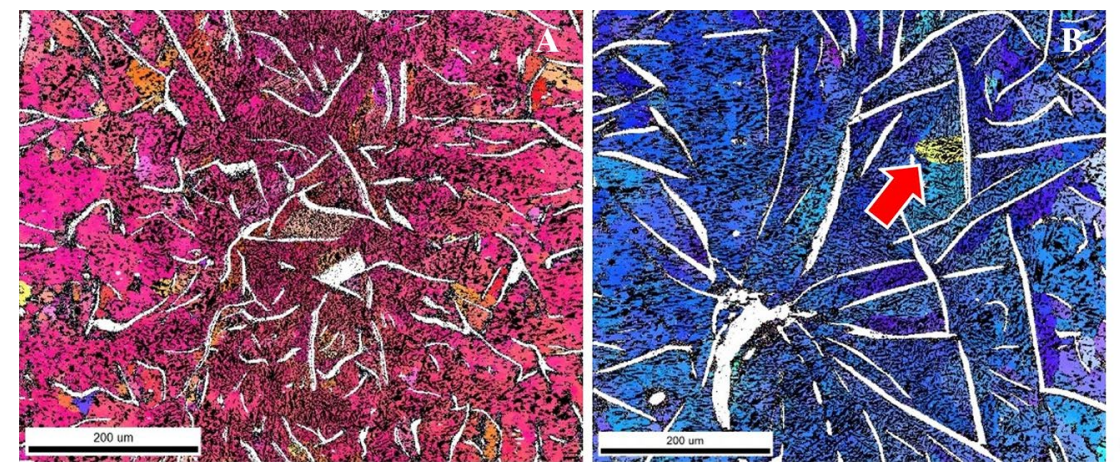

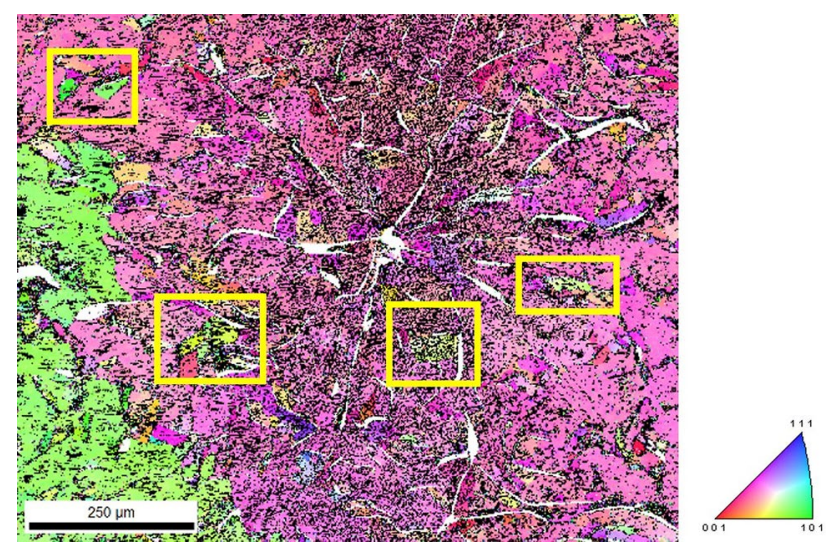

Fig. 12 EBSD orientation map for a sample of Melt A showing the presence of protrusions of austenite from the neighbor dendrite

Relatively small regions of differently oriented austenite are found inside the larger grain (red arrow, Fig. 11b). These regions seem to develop in contact with the flake graphite particles. Nevertheless, it must be pointed out that no one of these regions embrace a whole eutectic colony. They are limited just to a few square microns next to some of the graphite flakes.

The most likely option for the origin of these little regions of different orientation observed by EBSD is that they belong to adjacent dendrites that also got in contact with the graphite particles observed. It is significant that in the EBSD maps shown in Figs. 5, 6, and 11, all the small regions of austenite have mostly the same specific crystalline orientation. This most probably means that they belong to branches of the same grain. This grain is believed to have grown adjacent to the one revealed by EBSD; i.e., more deeply into the sample or in the other half of the sample that was removed by the sectioning. All the other small regions with different crystallographic orientation found can also be supposed to be small portions of other adjacent grains. This is caused by the $3 \mathrm{D}$ interaction existing among neighboring grains. Figure 12 shows how neighbor grains and their protrusions can sometimes be revealed together. The protrusions of the "green" grain into the "pink" one were indicated by yellow squares.

\section{Conclusions}

- EBSD results confirm that the solidification of LGI is dominated by the presence of dendritically grown portions of austenite that, after the use of the DAAS technique, can be observed by the naked eye.

- The combined use of EBSD and color etching revealed that all the eutectic colonies or cells have always the same crystallographic orientation as the primary austenite grains. This is true even for the case of hypereutectic melts solidified at low cooling rates. This finding refutes the existence of "eutectic grains" inside the primary austenite grains.

- The vast majority of austenite grain boundaries are found at LTF regions. In some less frequent cases, the austenite grain boundaries do not match LTF. In those cases, it seems that cooperative growth was established between a graphite precipitate and at least two different austenite dendrites.

\section{References}

1. F. Mampaey, Quantification of the solidification morphology of lamellar and spheroidal graphite cast iron. Int. J. Cast Met. Res. 11, 307-312 (1999)

2. G. Alonso, D. Stefanescu, P. Larrañaga, R. Suarez, Understanding compacted graphite iron solidification through interrupted solidification experiments. Int. J. Cast Met. Res. 20, 1-10 (2016)

3. G. Rivera, R. Boeri, J. Sikora, Revealing and characterising solidification structure of ductile cast iron. Mater. Sci. Technol. 18, 691-697 (2002)

4. G. Rivera, R. Boeri, J. Sikora, Research advances in ductile iron solidification. AFS Trans 111, 1-11 (2003)

5. A. Diószegi, K. Liu, I. Svensson, Inoculation of primary austenite in grey cast iron. Int. J. Cast Met. Res. 20, 68-72 (2007)

6. G. Rivera, R. Boeri, J. Sikora, Growth of eutectic austenite in free graphite cast irons. Key Eng. Mater. 457, 67-72 (2011) 
7. M. Motz, Microsegregation, an easily unnoticed influencing variable in the structural description of cast materials. Pract. Metallogr. 25, 285-293 (1988)

8. G. Rivera, R. Boeri, J. Sikora, Revealing the solidification structure of nodular iron. Cast Met. 8, 1-5 (1995)

9. G. Rivera, R. Boeri, J. Sikora, Solidification of gray cast iron. Scr. Mater. 50, 331-335 (2004)

10. A. Diószegi, On Microstructure Formation and Mechanical Properties in Grey Cast Iron, Ph.D. thesis, Linköping University, Sweden, 2004

11. M. König, Microstructure Formation During Solidification and Solid State Transformation in Compacted Graphite Iron, Ph.D. thesis, Jönköping University, Sweden, 2011

12. M. López, G. Rivera, J. Massone, R. Boeri, Study of the solidification structure of compacted graphite cast iron. Int. J. Cast Met. Res. 29, 266-271 (2016)

13. L. Elmquist, A. Diószegi, P. Svidró, Influence of primary austenite on the nucleation of eutectic cells. Key Eng. Mater. 457, 61-66 (2011)

14. H. Angus, Cast Iron: Physical and Engineering Properties (Butterworths, London, 1976)

15. D. Stefanescu, Metals Handbook, Casting (ASM International, Metals Park, 1988)
16. H. Fredriksson, U. Akerlind, Solidification and Crystallization Processing in Metals and Alloys, 1st edn. (Wiley, London, 2012)

17. E. Fras, M. Górny, Inoculation effects of cast iron. Arch. Foundry Eng. 12, 39-46 (2012)

18. D. Stefanescu, G. Alonso, P. Larrañaga, R. Suárez, On the stable eutectic solidification of iron-carbon-silicon alloys. Acta Mater. 103, 103-114 (2016)

19. G. Rivera, P. Calvillo, R. Boeri, Y. Houbaert, J. Sikora, Examination of the solidification macrostructure of spheroidal and flake graphite cast irons using DAAS and ESBD. Mater. Charact. 59, 1342-1348 (2008)

20. L. Elmquist, K. Soivio, A. Diószegi, Cast iron solidification structure and how it is related to defect formation. Mater. Sci. Forum 790-791, 441-446 (2014)

21. R. Ruxanda, L. Beltran-Sanchez, J. Massone, D. Stefanescu, On the eutectic solidification of spheroidal graphite iron-an experimental and mathematical modeling approach-, in Proceedings of Cast Iron Division, AFS 105th Casting Congress, Dallas, Texas, 2001, pp. 37-48

Publisher's Note Springer Nature remains neutral with regard to jurisdictional claims in published maps and institutional affiliations. 